\title{
Article
}

\section{Long-Acting Reversible Contraception: Placement, Continuation, and Removal Rates at an Inner-City Academic Medical Center Clinic}

\author{
Aliye Runyan ${ }^{1}$, Robert A. Welch ${ }^{2}$, Katherine J. Kramer ${ }^{3}$, Sarah Cortez ${ }^{4}$, LeAnne J. Roberts ${ }^{4}$, \\ Clementina Asamoah ${ }^{4}$, Sarah Ottum ${ }^{5}$, Jessica Sanders ${ }^{6}$, Adib Shafi ${ }^{7}$ and Maurice-Andre Recanati ${ }^{8, *}$ \\ 1 Department of Obstetrics and Gynecology, Westchester Medical Center, Valhalla, NY 10595, USA; \\ alrunyan@gmail.com \\ 2 Department of Obstetrics and Gynecology, Hurley Medical Center, Flint, MI 48503, USA; \\ rwelch2@hurleymc.com \\ 3 Department of Obstetrics and Gynecology, St. Vincent's Catholic Medical Centers, New York, NY 10011, USA; \\ katherinekramer@gmail.com \\ 4 Department of Obstetrics and Gynecology, Wayne State University, Detroit, MI 48202, USA; \\ sarah.cortez@wayne.edu (S.C.); lroberts@med.wayne.edu (L.J.R.); asamoahc@gmail.com (C.A.) \\ 5 Department of Surgery, Wayne State University, Detroit, MI 48202, USA; Sottum@med.wayne.edu \\ 6 Department of Obstetrics and Gynecology, University of Utah, Salt Lake City, UT 84132, USA; \\ jessica.sanders@hsc.utah.edu \\ check for \\ updates \\ Citation: Runyan, A.; Welch, R.A.; \\ Kramer, K.J.; Cortez, S.; Roberts, L.J.; \\ 7 Department of Computer Science, Wayne State University, Detroit, MI 48202, USA; fj9079@wayne.edu \\ 8 NIH-Women's Reproductive Health Research (WRHR) Scholar, Department of Obstetrics and Gynecology, \\ Wayne State University, Detroit, MI 48202, USA \\ * Correspondence: marecanati@wayne.edu
} Asamoah, C.; Ottum, S.; Sanders, J.; Shafi, A.; Recanati, M.-A.

Long-Acting Reversible Contraception: Placement, Continuation, and Removal Rates at an Inner-City Academic Medical Center Clinic. J. Clin. Med. 2021, 10, 1918. https://doi.org/10.3390/ jcm10091918

Academic Editor:

Giuseppe Benagiano

Received: 28 February 2021

Accepted: 21 April 2021

Published: 28 April 2021

Publisher's Note: MDPI stays neutral with regard to jurisdictional claims in published maps and institutional affiliations.

Copyright: (C) 2021 by the authors. Licensee MDPI, Basel, Switzerland. This article is an open access article distributed under the terms and conditions of the Creative Commons Attribution (CC BY) license (https:// creativecommons.org/licenses/by/ $4.0 /)$.

\begin{abstract}
Long-Acting Reversible Contraception (LARCs) has the potential to decrease unintended pregnancies but only if women can easily access a requested method. Retrospective electronic chart review identified women desiring LARC placement over a one-year period ending 31 December 2016. Most of the 311 insertions were for family planning, with 220 new insertions and 60 replacements. Delays occurred in $38 \%(n=118)$ of patients, averaged $5 \pm 5$ weeks, and $47 \%$ received interval contraception. Reasons included absence of qualified provider $(n=44,37 \%)$, pending cultures $(n=31,26 \%)$, and Mirena availability. Teenage LARC use favored Nexplanon whereas older women preferred Mirena $(p<0.01)$. Of the $11 \%$ choosing early LARC removal, a significant number were African Americans $(p=0.040)$ or teenagers $(p=0.048)$. Retention time varied by device type; most patients switched to other contraceptives. No patients experienced IUD expulsion. Understanding barriers, attempting to remedy them, and addressing the side effects associated with LARC use is of importance in this inner-city patient population in the United States.
\end{abstract}

Keywords: long-acting reversible contraception; intrauterine device; LARC placement delays; removal rates; inner-city clinic

\section{Introduction}

About six million pregnancies occur yearly in the United States, with approximately $45-51 \%$ of these unintended [1]. Compared to other industrialized nations, this rate is substantially higher [2], and worldwide $44 \%$ of pregnancies are unintended, with rates as high as $65 \%$ in developing nations [3]. Although unintended pregnancies affect all women, rates were disproportionately highest among those who were cohabitating, below the poverty line or were non-Hispanic Blacks [1]. About 54\% experiencing unintended pregnancy reported using contraception at the time they conceived [4]. Inconsistent method use accounts for $90 \%$ of these pregnancies rather than method failure (10\%) [5]. About $25 \%$ of at-risk women experience one or more months with a gap in contraceptive use [6]. Lack of college education, ambivalence about pregnancy, being Black, being 35-44 years of age, 
method-related difficulties, side effects and dissatisfaction with the current method were strongly associated with inconsistent contraceptive use [7].

Of the 61 million U.S. women aged $14-44$ years old, $61.7 \%$ are currently using contraception [8]. Common methods include oral contraceptives (16-38\%), male condoms (9.4-32\%), long-acting reversible contraceptives (LARC) (7.2-12\%), and female sterilization $(15.5-25 \%)[5,9]$. These rates are comparable with other nations such as Europe (10-32\%) and Australia (7\%) [10]. Failure rates in the first year are $9 \%, 18 \%, 0.05-0.8 \%$, and $0.1-0.8 \%$, respectively [11]. Reasons for inconsistent use of user-dependent methods include absence from home, depletion of supplies, illness, lack of inclination, perception of being at low risk for pregnancy, attitudes about pregnancy, and experiences with unintended pregnancy $[4,5]$.

LARC methods of contraception are highly effective yet may be underused [11]. Only about $12 \%$ of women currently employ LARC contraception, of whom $10 \%$ use intrauterine devices (IUDs) while 1.3\% have subdermal implants (SDIs) [9]. Barriers to LARC utilization include patient lack of knowledge [12], bias in counselling by healthcare providers [13,14], lack of provider training and competency [15], and the up-front cost of these devices [16]. When patients are well educated, and when costs are not a factor, such as for female OBGYN residents, 53\% chose LARC methods [17]. Similarly, for patients enrolled in the CHOICE Project, which provided education and no-cost birth control, a majority of women $(67 \%)$ choose LARCs [18]. Because LARC methods are "forgettable," effectiveness is user-independent, and they eliminate the common shortfalls previously described for other contraceptives. LARCs have some of the highest rates of continuation after one year- $84 \%$ for Implanon [11] and greater than $80 \%$ for IUDs [11] — with patient satisfaction rates mirroring continuation rates $[19,20]$. These devices have been shown to be safe [21] and effective in all women regardless of parity [22] and their use has been increasing in younger women [23].

In order to prevent unintended pregnancies and their associated financial [24] and social [25] costs, effective contraceptives, such as LARCs, must be readily accessible and barriers to insertion minimized. Since nearly half of patients intending to use an IUD failed to return for placement during a subsequent visit [26], single visit protocols ensure that more women have access to contraception in a timely manner. The insurance restriction of combining a well-woman exam with IUD insertion, the availability of the device, and pre-insertion screening all may cause such delays. Multiple studies have shown that in women with asymptomatic sexually transmitted diseases, IUD placement did not increase the risk of pelvic inflammatory disease (PID) $[27,28]$. Thus, screening can be done at the time of insertion and treatment given subsequently [29].

For a contraceptive to be effective it must be continuously used, yet a minority of patients opt to discontinue their method for reasons other than planning pregnancy [30]. Common adverse effects of LARCs include abnormal bleeding, amenorrhea, dysmenorrhea, pelvic pain [31] and, for implants, rod migration, mood swings, and headaches [32]. While LARCs are FDA approved to remain in place for 3 to 10 years, women who experience intolerable side effects may opt for "early" removal [33-35]. Many patients requesting removal of LARCs also complained of a lack of disclosure of all possible side effects and encountered delays after they requested removal, raising concerns about provider's attitudes and respect for body autonomy [36,37].

LARC utilization patterns at the downtown campus of the Detroit Medical Center are likely to reflect those of other large urban populations. Little is known, however, about LARC acceptance by underserved women in the impersonal environment of such large urban medical centers that are staffed by resident physicians and nurse practitioners. The impact of high-volume clinic care on the acceptance of LARCs may have significant population health implications. The purpose of this study was to evaluate LARC utilization in the setting of a large urban academic center. 


\section{Materials and Methods \\ Patient Selection}

Under IRB approval (WSU 074517MP2E), a retrospective electronic health record (EHR) review was performed to identify women who requested LARC placement in the resident clinic for a one-year period from 1 January through 31 December 2016. Included were non-pregnant women [38] desiring LARC contraception. IUDs (Mirena and Paragard) and implants (Nexplanon) were analyzed separately. Information from each patient included: demographic data, prior contraceptive method, proximity to previous childbirth, date of LARC request, date of LARC placement, type of device, provider (resident, physician or nurse practitioner), reason device was inserted (e.g., family planning, replace expiring device, abnormal bleeding) and an explanation for delays, defined as failure to place a device at the initial visit. Records were reviewed for prescription of bridging contraceptive methods during this delay period. Patients receiving LARCs during the study period were followed for an additional year to identify those requesting early LARC removal, the date of this request, reason, and actual date the device was removed, as well as their new contraceptive method, if any.

Quantile-quantile plots were used to examine normality of numeric variables. Median differences were examined using the Kruskal-Wallis or Mann-Whitney U tests, as appropriate. Differences in proportions were tested using the Fisher's exact test, as appropriate. We used logistic regression to examine magnitudes of association adjusting for potentially confounding factors. Statistical significance was considered to be $p<0.05$ or $95 \%$ confidence interval $(\mathrm{CI})$, not including the null estimate of association (i.e., odds ratio $(\mathrm{OR})=1.0$ ).

\section{Results}

This study included 311 participants. LARC device utilization by age and ethnicity is shown in Table 1.

Table 1. Utilization of Long-Acting Reversible Contraception by Age and Ethnicity.

\begin{tabular}{|c|c|c|c|c|}
\hline & $\mathbf{N}(\%)$ & Mirena & Paragard & Nexplanon \\
\hline Average Age $( \pm S D)$ & $28.2( \pm 7.9)$ & $30.9( \pm 7.6)$ & $28.4( \pm 7.4)$ & $24.1( \pm 6.8)$ \\
\hline Age range & $13-51$ & $14-51$ & $17-46$ & $13-44$ \\
\hline African American & $266(85)$ & 146 & 18 & 102 \\
\hline Middle Eastern & $18(6)$ & 3 & 14 & 1 \\
\hline Asian & $15(5)$ & 2 & 13 & 0 \\
\hline White & $10(3)$ & 5 & 2 & 3 \\
\hline Hispanic & $2(<1)$ & 1 & 0 & 1 \\
\hline Family Planning-New device insertions & $220(71)$ & 90 & 43 & 87 \\
\hline $\begin{array}{c}\text { Family Planning-Replacement of expired } \\
\text { device }\end{array}$ & $60(19)$ & 36 & 4 & 20 \\
\hline Abnormal Uterine Bleeding & $31(10)$ & 31 & 0 & 0 \\
\hline Total & $311(100)$ & 157 & 47 & 107 \\
\hline
\end{tabular}

\subsection{Indication for Device Placement}

The majority of LARCs were placed for family planning indications $(n=280)$ with $n=220$ new device insertions and $n=60$ replacement of an expired device. A significant number of new devices placed included Nexplanon and Paragard $(n=87, p<0.004$; and $n=43, p<0.001$, respectively), compared to all insertions. A significant number of new family planning insertions were requested by Middle Eastern women $(n=17, p=0.014)$, compared to all insertions for the indication of family planning. Abnormal uterine bleeding accounted for the remainder of insertions $(n=31)$, all of which were Mirena. 


\subsection{Device Distribution by Race}

Across all cases (new insertions and replacements), Mirena was the most frequently chosen LARC $(n=157,50 \%)$, followed by Nexplanon $(n=107,34 \%)$ and Paragard $(n=47$, $15 \%$ ) as shown in Figure 1. African Americans chose Mirena significantly more than did the other races (Middle Eastern, Asian, White and Hispanic), 55\% vs. 24\% (146/266 vs. $11 / 45, p<0.001)$. Similarly, African Americans chose Nexplanon significantly more often than did the other races, $38 \%$ vs. $11 \%(102 / 266$ vs. $5 / 45, p<0.001)$. On the other hand, the other groups, particularly Middle Eastern, chose Paragard significantly more than did African Americans, $64 \%$ vs. just $7 \%$ (29/45 vs. $18 / 266, p<0.001)$.

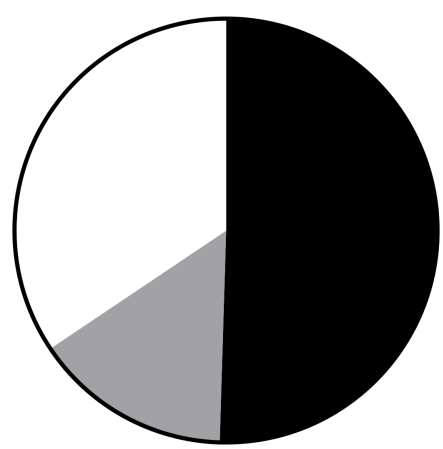

(A)

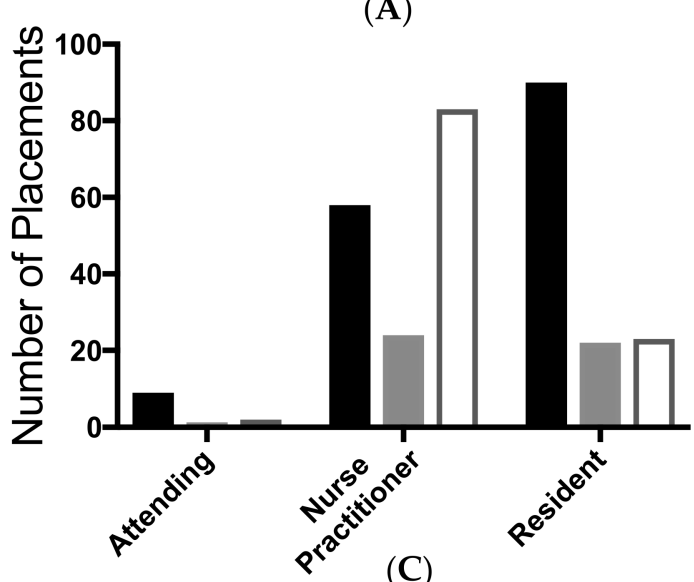

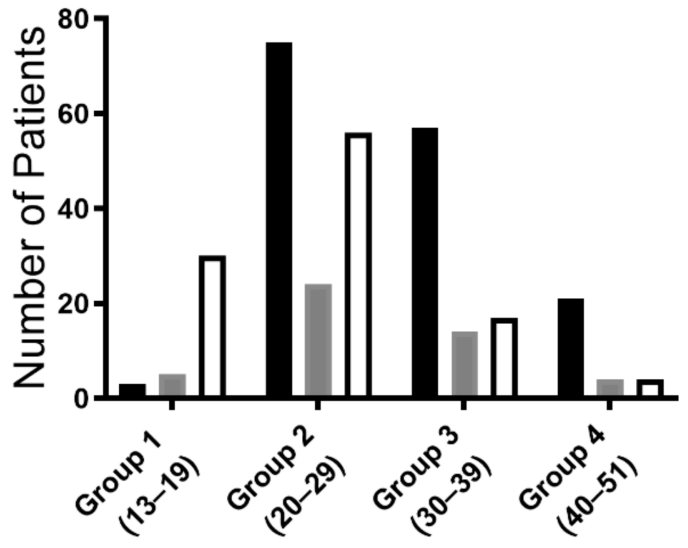

(B)

Figure 1. LARC devices placed in 2016 (A) by device type $(n=311)$; (B) by age group; (C) by provider type.

\subsection{Device Distribution by Age}

For analysis purposes, age ranges were divided into four groups: group 1: 13-19 years old $(n=38)$, group 2: 20-29 $(n=155)$, group 3: 30-39 $(n=89)$, group 4: 40-51 $(n=29)$. A significant number of patients from group 4 chose Mirena $(n=21, p=0.01)$, while a significant number of teenagers chose Nexplanon $(n=30, p<0.001)$, as shown in Figure 1.

\subsection{Analysis of Delays in LARC Placement}

Out of 311 patients, $38 \%$ (118) experienced delays requiring more than one visit for the placement of their LARC, and the mean length of the delay was 4.8 weeks \pm 4.8 (SD, range 1 week to 7 months).

African American women were significantly more likely to experience a delay in LARC placement compared to other races taken as a whole $(108 / 266=41 \%$ vs. $10 / 45=22 \%$, $p=0.020)$. There was no significant difference, however, in the duration of delay by race.

Those choosing Mirena were significantly more likely to experience a delay in LARC placement compared to the other two devices taken as a whole $(69 / 157=59 \%$ vs. $49 / 154=32 \%$, $p=0.035)$. There was no significant difference, however, in the duration of delay by device.

Stated reasons for delaying LARC placement included absence of a qualified provider ( $n=44,37 \%)$, pending gonorrhea/chlamydial test results $(n=31,26 \%)$, and reason un- 
known $(n=30,25 \%)$, with the remainder consisting of scheduling issues $(n=2)$, recent intercourse $(n=2)$, abnormal pap $(n=1)$, unexplained vaginal bleeding $(n=1)$, pending endometrial biopsy $(n=4)$, retained $\operatorname{IUD}(n=2)$ and uterine abnormality $(n=1)$ (Figure 2$)$. A significant number of patients who were delayed for pending gonorrhea/chlamydial cultures had chosen Mirena compared to all who were delayed ( $p=0.007, n=25$ of 31 compared to 69 of 118). Patients who chose Nexplanon had significantly less delay in placement ( $p=0.020$ ) when the device was inserted by residents $(n=8$ of 35$)$ as opposed to nurse practitioners ( $n=26$ of 35 ). No other association was found between the delay in LARC placement and the type of medical provider. No significant association was found between patient age and delay in LARC placement. Forty-seven percent of women experiencing delays were bridged with contraceptives including condoms $(n=24,21 \%)$ or continuation of existing method $(n=29,26 \%)$ such as Depo-Provera or IUD, while the rest were either not offered contraception or no documentation could be found.

(A)

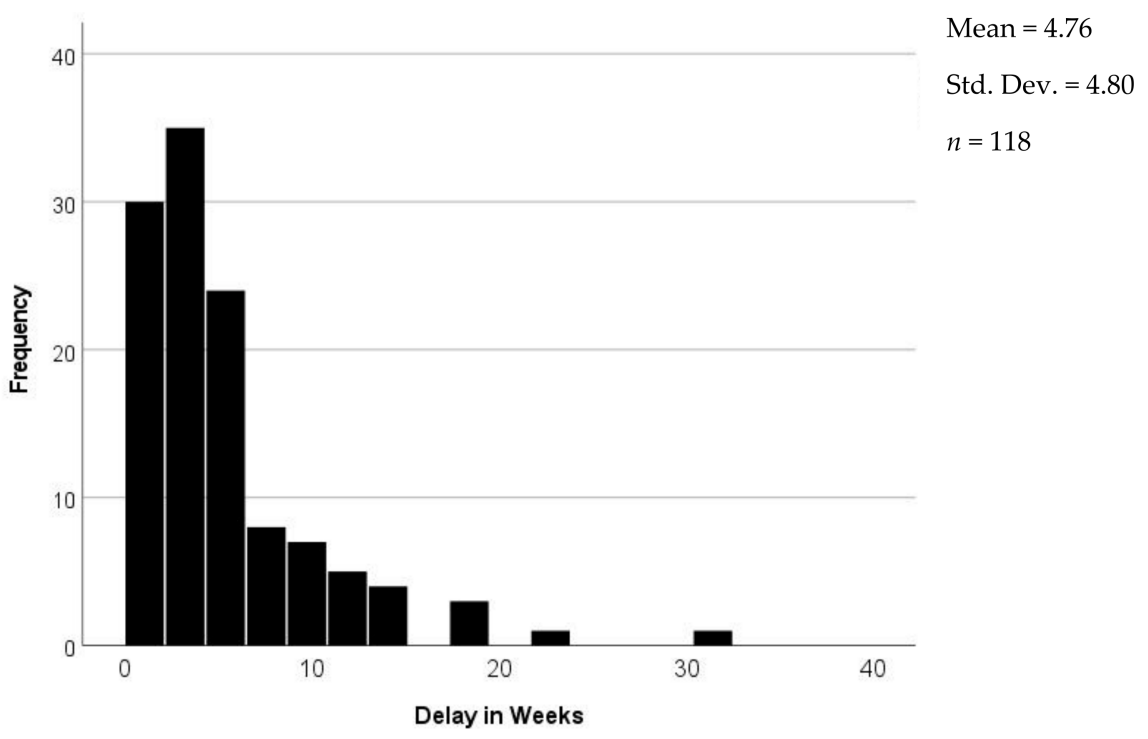

(B)
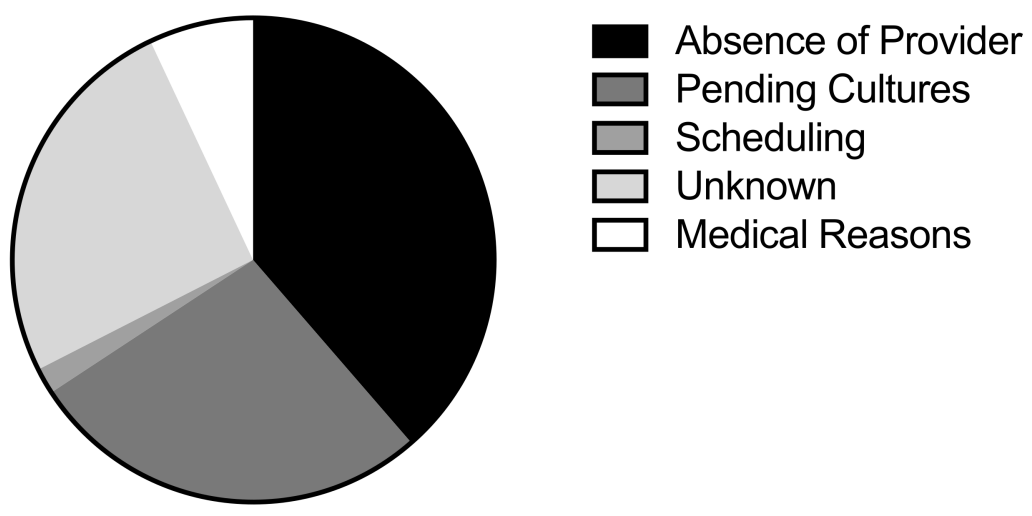

Figure 2. Delay in LARC Placement. (A) Length of delay; (B) reasons for delay.

\subsection{Analysis of Device Removal}

Thirty-four women chose to have their LARC device removed (17 Mirena, 16 Nexplanon, 1 Paragard). Out of this group, $n=24$ (71\%) were new insertions. The average length of retention for those who chose removal was 162 days (range 8-356 days) but varied significantly $(p=0.02)$ by device type: Mirena ( 4.2 months $\pm 2.8 \mathrm{SD})$ vs. Nexplanon 
(6.8 months $\pm 3.2 \mathrm{SD}$ ) (Figure 3). No significant relation was found with the type of provider placing the device. Nearly all the women who chose to remove their LARC were African American $(33 / 34, p=0.040)$. A significant number who chose removal were teenagers $(n=8, p=0.048)$. Only $3 \%$ ( 1 of $34, p=0.39)$ discontinued Paragard, despite Paragard comprising $15 \%$ of all devices (47 of 311). No patients experienced IUD expulsion.

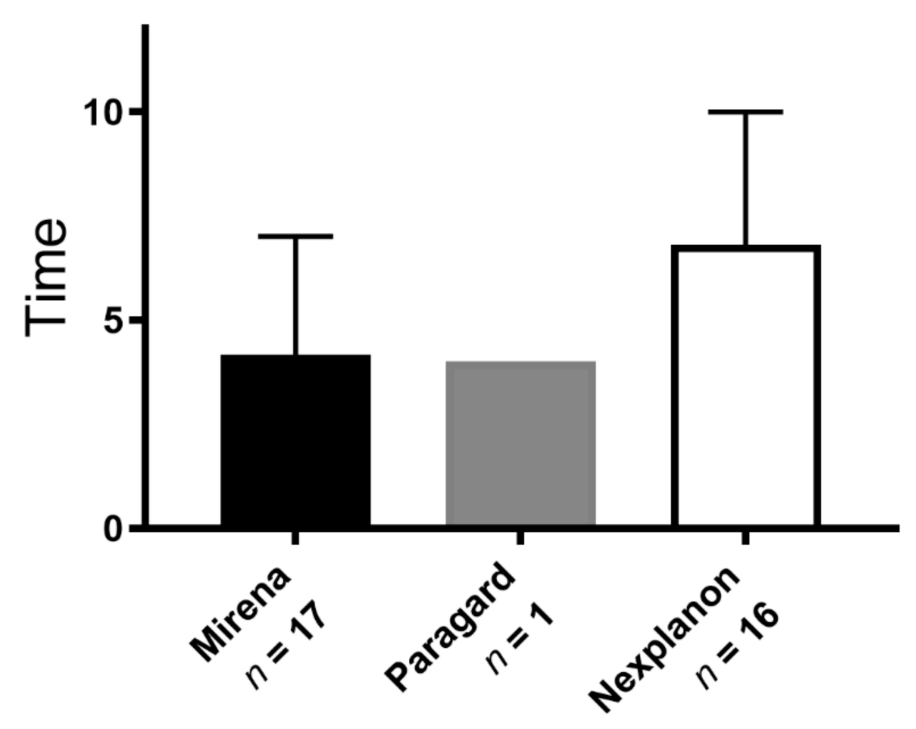

Figure 3. Thirty-four (11\%) women chose early removal of their LARC. Mean time (in months) from insertion to removal varied significantly by device type. Error bars represent SD.

\subsection{Analysis of Switching out of LARC Method}

Of the 34 women who removed their LARC, twenty-four elected to switch to an alternate method of contraception. These included: OCPs $(n=10)$, depot-medroxyprogesterone acetate $(n=9)$, Paragard $(n=1)$, patch $(n=1)$, Mirena $(n=1)$, NuvaRing $(n=1)$, and barrier methods $(n=1)$. Of all age groups, teenagers were also most likely to switch to another form of birth control $(n=8, p=0.018)$.

\section{Discussion}

\subsection{Delay in Placement}

The majority of LARC placements were for family planning and $21 \%(60 / 280)$ of placements consisted of replacement of an expiring device. Our experience in this urban clinic demonstrates that $38 \%$ of patients requesting LARC experienced significant delays in placement. Lack of provider education and particularly the belief that IUD placement requires knowledge of the results of gonorrhea/chlamydia testing [39], the absence of a qualified providers, and scheduling issues accounted for about two-thirds of these delays (Figure 2). Mirena was the most frequently chosen LARC, but women opting for this device experienced the greatest delays due to pending cultures $(p=0.022)$ and because of lack of device availability.

Unintended pregnancy remains a major public health issue [1]. LARC contraceptives, when placed on the day that the patient requests it, provides immediate protection from unintended pregnancy. In women where it is "reasonably certain" [38] that they are not pregnant, same day placement should be the goal [40]. When compared to patients requesting hormonal methods, $95 \%$ women $(697 / 737)$ who met the criteria walked out with a prescription. These factors may be addressed through provider education and improved clinic management. Clinicians should offer bridging contraception to prevent pregnancy regardless of the reason for the delay in LARC placement. 


\subsection{Early Removal of Device}

We found that both subdermal implants (SDI) and IUDs had high continuation rates $(90 \%)$ and low numbers of complications in the first-year post-insertion, consistent with other studies $[19,35,41]$. These rates surpass those of short-acting contraceptives such as the patch (10\%) and the pill (32\%) [42]. Unlike other studies [41], we found that removal rates were not associated with type of provider placing the device. This may be due to the formal training clinicians practicing at our institution receive which ensures that patients universally receive adequate pre-placement counselling.

About $10 \%$ of LARCs in our study were inserted in teenagers, reflecting a growing acceptance of long-acting contraceptives in this age group [43]. Similar to other studies $[33,44]$, we observed that SDIs were prescribed significantly more in teens. This may be due to an ongoing bias from less informed physicians on the use of IUDs in nulliparous patients [45], and in particularly teens [14]. This group also experienced a significantly higher number of complications, particularly spotting, but were most likely to switch to another form of birth control. Conversely, older women were more likely to opt for an IUD, particularly Mirena, as this method is also indicated for the treatment of abnormal uterine bleeding. Similar to other studies, we found that this age group tended to have high retention rates for their LARC [30]. Future studies may also examine the decision to choose LARCs over other methods where metabolic [46] and vascular effects, weight gain, body image [47] and sexual behavior [48] impact patient wellbeing.

Concerns involving early removal of LARCs go beyond the simple cost-effectiveness calculation and include risks of unintended pregnancies associated with no contraception or suboptimal protection. Frequently, patients present to clinic requesting removal of their device because of pain, changes in bleeding patterns, mood swings, weight gain or other reasons. Studies have shown that these women tended to reluctantly tolerate these side effects but eventually reached a tipping point [32]. A close follow up with patients who received LARCs may help ensure that clinicians can intervene in alleviating the side effects of the LARC. While some physicians tend to be reluctant to remove LARCs, it is critical that they respect patient autonomy and support a woman's decision-making around contraceptive use [36]. Teaching patients about IUD self-removal [49] could have a positive impact on reproductive autonomy. The effects of women seeking removal from other willing clinicians, or removing the device on their own, may influence the results of our study and will be examined by prospective trials in the future.

A strength of our study is the inclusion of African American women of all age ranges. The study was limited by using a single urban health clinic where the majority of patients had public health insurance [25]. Further study in different geographic areas or in women with private insurance may alter our findings or limit generalizability. If patients received care for LARC-related issues at other clinics, or lost Medicaid eligibility, continuation rates may be falsely high. While the electronic health record (EHR) was used to access contraception encounter data, the accuracy of the records has the potential for incomplete data [50], which may affect results. One such limitation is the inability of our EHR to ascertain the number of women who intended to be on LARC but were unable to obtain it and never returned.

\section{Conclusions}

Although the American College of Obstetrics and Gynecology recommends sameday LARC placement in eligible patients, this study elucidates some of the challenges encountered in making same-day insertion practical in a large urban clinic. Realizing that women requesting family planning visits should be considered urgent appointments can help protect women from undesired pregnancy. Controlling device inventory, having trained providers present and educating on latest guidelines are necessary to fulfill patient expectations. In all circumstances, clinicians must offer the patient a reliable means of contraception in the interim. Reasons why women chose LARC removal and choose other, less reliable forms of contraception need further study. 
Author Contributions: Conceptualization, A.R. and M.-A.R.; methodology, K.J.K. and. S.C.; software, S.O., J.S. and A.S.; validation, S.O., J.S. and S.O.; formal analysis, A.S. and S.O.; investigation, L.J.R.; resources, S.C. and R.A.W.; data curation, S.O.; writing-original draft preparation, M.-A.R., R.A.W. and K.J.K.; writing-review and editing, R.A.W. and A.R.; visualization, C.A.; supervision, M.-A.R.; project administration, K.J.K.; funding acquisition, M.-A.R. All authors have read and agreed to the published version of the manuscript.

Funding: This research was supported under NIH-Women's Reproductive Health Research Career Development Award (K-12HD001254).

Institutional Review Board Statement: The Wayne State University Institutional Review Board approved IRB\# 074517MP2E, LARC Placement, Continuation and Removal Rates in the DMC ObGyn clinics (Protocol \# 1707000720).

Informed Consent Statement: This is a retrospective chart review. All data was de-identified and informed consent was waved by the IRB.

Data Availability Statement: The datasets that support the findings of this study are available from the corresponding author (M.-A.R.) upon reasonable written request.

Acknowledgments: This research was made possible by the work and dedication of all the obstetrics and gynecology residents at Wayne State University and by the faculty and staff at the Detroit Medical Center. In particular, the Sorin Draghichi laboratory helped provide statistical analysis. We also wish to thank the NIH-Women's Reproductive Health Research Career Development Award at Wayne State University for ongoing research and support.

Conflicts of Interest: The authors declare no conflict of interest.

\section{References}

1. Finer, L.B.; Zolna, M.R. Declines in Unintended Pregnancy in the United States, 2008-2011. N. Engl. J. Med. 2016, 374, 843-852. [CrossRef] [PubMed]

2. Sedgh, G.; Singh, S.; Hussain, R. Intended and unintended pregnancies worldwide in 2012 and recent trends. Stud. Fam. Plan. 2014, 45, 301-314. [CrossRef] [PubMed]

3. Bearak, J.; Popinchalk, A.; Alkema, L.; Sedgh, G. Global, regional, and subregional trends in unintended pregnancy and its outcomes from 1990 to 2014: Estimates from a Bayesian hierarchical model. Lancet Glob. Health 2018, 6, e380-e389. [CrossRef]

4. Jones, R.K.; Darroch, J.E.; Henshaw, S.K. Contraceptive use among U.S. women having abortions in 2000-2001. Perspect. Sex. Reprod. Health 2002, 34, 294-303. [CrossRef] [PubMed]

5. Frost, J.J.; Darroch, J.E. Factors associated with contraceptive choice and inconsistent method use, United States, 2004 . Perspect. Sex. Reprod. Health 2008, 40, 94-104. [CrossRef] [PubMed]

6. Frost, J.J.; Singh, S.; Finer, L.B. U.S. women's one-year contraceptive use patterns, 2004. Perspect. Sex. Reprod. Health 2007, 39, 48-55. [CrossRef] [PubMed]

7. Frost, J.J.; Singh, S.; Finer, L.B. Factors associated with contraceptive use and nonuse, United States, 2004. Perspect. Sex. Reprod. Health 2007, 39, 90-99. [CrossRef] [PubMed]

8. Daniels, K.; Mosher, W.D. Contraceptive Methods Women Have Ever Used: United States, 1982-2010; National Health Statistics Report; National Center for Health Statistics: Hyattsville, MD, USA, 2013; pp. 1-15.

9. Daniels, K.; Daugherty, J.; Jones, J. Current Contraceptive Status among Women Aged 15-44: United States, 2011-2013; NCHS Data Brief; National Center for Health Statistics: Hyattsville, MD, USA, 2014; pp. 1-8.

10. Eeckhaut, M.C.; Sweeney, M.M.; Gipson, J.D. Who is using long-acting reversible contraceptive methods? Findings from nine low-fertility countries. Perspect. Sex. Reprod. Health 2014, 46, 149-155. [CrossRef]

11. Trussell, J. Contraceptive failure in the United States. Contraception 2011, 83, 397-404. [CrossRef]

12. Forrest, J.D. U.S. women's perceptions of and attitudes about the IUD. Obstet. Gynecol. Surv. 1996, 51, S30-S34. [CrossRef]

13. Madden, T.; Allsworth, J.E.; Hladky, K.J.; Secura, G.M.; Peipert, J.F. Intrauterine contraception in Saint Louis: A survey of obstetrician and gynecologists' knowledge and attitudes. Contraception 2010, 81, 112-116. [CrossRef]

14. Diaz, V.A.; Hughes, N.; Dickerson, L.M.; Wessell, A.M.; Carek, P.J. Clinician knowledge about use of intrauterine devices in adolescents in South Carolina AHEC. Fam. Med. 2011, 43, 407-411.

15. Phillips, J.; Sandhu, P. Barriers to implementation of long-acting reversible contraception: A systematic review. J. Am. Assoc. Nurse Pract. 2018, 30, 236-243. [CrossRef] [PubMed]

16. Trussell, J.; Lalla, A.M.; Doan, Q.V.; Reyes, E.; Pinto, L.; Gricar, J. Cost effectiveness of contraceptives in the United States. Contraception 2009, 79, 5-14. [CrossRef] [PubMed]

17. Evans, M.L.; Espey, E.; Ogburn, T.; Zite, N.B. Use of Long-Acting Reversible Contraception by Obstetrics and Gynecology Residents: An Examination of Access for All Women. Obstet. Gynecol. 2018, 131, 538-541. [CrossRef] [PubMed] 
18. Secura, G.M.; Allsworth, J.E.; Madden, T.; Mullersman, J.L.; Peipert, J.F. The Contraceptive CHOICE Project: Reducing barriers to long-acting reversible contraception. Am. J. Obstet. Gynecol. 2010, 203, 115.e1-115.e7. [CrossRef]

19. Peipert, J.F.; Zhao, Q.; Allsworth, J.E.; Petrosky, E.; Madden, T.; Eisenberg, D.; Secura, G. Continuation and satisfaction of reversible contraception. Obstet. Gynecol. 2011, 117, 1105-1113. [CrossRef] [PubMed]

20. Rosenstock, J.R.; Peipert, J.F.; Madden, T.; Zhao, Q.; Secura, G.M. Continuation of reversible contraception in teenagers and young women. Obstet. Gynecol. 2012, 120, 1298-1305. [CrossRef]

21. Curtis, K.M.; Tepper, N.K.; Jatlaoui, T.C.; Berry-Bibee, E.; Horton, L.G.; Zapata, L.B.; Simmons, K.B.; Pagano, H.P.; Jamieson, D.J.; Whiteman, M.K. US medical eligibility criteria for contraceptive use, 2016. Morb. Mortal. Wkly. Rep. Recomm. Rep. 2016, 65, 1-103. [CrossRef]

22. Lohr, P.A.; Lyus, R.; Prager, S. Use of intrauterine devices in nulliparous women. Contraception 2017, 95, 529-537. [CrossRef]

23. Logan, R.G.; Thompson, E.L.; Vamos, C.A.; Griner, S.B.; Vazquez-Otero, C.; Daley, E.M. Is Long-Acting Reversible Contraceptive Use Increasing? Assessing Trends Among U.S. College Women, 2008-2013. Matern. Child Health J. 2018. [CrossRef] [PubMed]

24. Sonfield, A.; Kost, K.; Gold, R.B.; Finer, L.B. The Public Costs of Births Resulting from Unintended Pregnancies: National and State-Level Estimates. Perspect. Sex. Reprod. Health 2011, 43, 94-102. [CrossRef] [PubMed]

25. Dehlendorf, C.; Rodriguez, M.I.; Levy, K.; Borrero, S.; Steinauer, J. Disparities in family planning. Am. J. Obstet. Gynecol. 2010, 202, 214-220. [CrossRef] [PubMed]

26. Bergin, A.; Tristan, S.; Terplan, M.; Gilliam, M.L.; Whitaker, A.K. A missed opportunity for care: Two-visit IUD insertion protocols inhibit placement. Contraception 2012, 86, 694-697. [CrossRef] [PubMed]

27. Turok, D.K.; Eisenberg, D.L.; Teal, S.B.; Keder, L.M.; Creinin, M.D. A prospective assessment of pelvic infection risk following same-day sexually transmitted infection testing and levonorgestrel intrauterine system placement. Am. J. Obstet. Gynecol. 2016, 215, 599.e1-599.e6. [CrossRef] [PubMed]

28. Jatlaoui, T.C.; Simmons, K.B.; Curtis, K.M. The safety of intrauterine contraception initiation among women with current asymptomatic cervical infections or at increased risk of sexually transmitted infections. Contraception 2016, 94, 701-712. [CrossRef]

29. American College of Obstetricians and Gynecologists. ACOG Practice Bulletin No. 121: Long-acting reversible contraception: Implants and intrauterine devices. Obstet. Gynecol. 2011, 118, 184-196. [CrossRef]

30. Romano, M.J.; Toye, P.; Patchen, L. Continuation of long-acting reversible contraceptives among Medicaid patients. Contraception 2018. [CrossRef]

31. Hubacher, D. Copper intrauterine device use by nulliparous women: Review of side effects. Contraception 2007, 75, S8-S11. [CrossRef]

32. Hoggart, L.; Newton, V.L.; Dickson, J. “I think it depends on the body, with mine it didn't work": Explaining young women's contraceptive implant removal. Contraception 2013, 88, 636-640. [CrossRef]

33. Berenson, A.B.; Tan, A.; Hirth, J.M. Complications and continuation rates associated with 2 types of long-acting contraception. Am. J. Obstet. Gynecol. 2015, 212, 761.e1-761.e8. [CrossRef] [PubMed]

34. Chiles, D.P.; Roberts, T.A.; Klein, D.A. Initiation and continuation of long-acting reversible contraception in the United States military healthcare system. Am. J. Obstet. Gynecol. 2016, 215, 328.e1-328.e9. [CrossRef]

35. Grunloh, D.S.; Casner, T.; Secura, G.M.; Peipert, J.F.; Madden, T. Characteristics associated with discontinuation of long-acting reversible contraception within the first 6 months of use. Obstet. Gynecol. 2013, 122, 1214-1221. [CrossRef] [PubMed]

36. Amico, J.R.; Bennett, A.H.; Karasz, A.; Gold, M. "I wish they could hold on a little longer": physicians' experiences with requests for early IUD removal. Contraception 2017, 96, 106-110. [CrossRef] [PubMed]

37. Foster, D.G.; Grossman, D.; Turok, D.K.; Peipert, J.F.; Prine, L.; Schreiber, C.A.; Jackson, A.V.; Barar, R.E.; Schwarz, E.B. Interest in and experience with IUD self-removal. Contraception 2014, 90, 54-59. [CrossRef] [PubMed]

38. Curtis, K.M.; Jatlaoui, T.C.; Tepper, N.K.; Zapata, L.B.; Horton, L.G.; Jamieson, D.J.; Whiteman, M.K. U.S. Selected Practice Recommendations for Contraceptive Use, 2016. Morb. Mortal. Wkly. Rep. Recomm. Rep. 2016, 65, 1-66. [CrossRef]

39. Long-Acting Reversible Contraception Working Group. ACOG Committee Opinion no. 450: Increasing use of contraceptive implants and intrauterine devices to reduce unintended pregnancy. Obstet. Gynecol. 2009, 114, 1434-1438. [CrossRef] [PubMed]

40. Morroni, C.; Findley, M.; Westhoff, C. Does using the "pregnancy checklist" delay safe initiation of contraception? Contraception 2017, 95, 331-334. [CrossRef] [PubMed]

41. Amico, J.; Wu, J. Providing Long-Acting Reversible Contraception in an Academic Family Medicine Center. Fam. Med. 2015, 47, 727-731.

42. Raine, T.R.; Foster-Rosales, A.; Upadhyay, U.D.; Boyer, C.B.; Brown, B.A.; Sokoloff, A.; Harper, C.C. One-year contraceptive continuation and pregnancy in adolescent girls and women initiating hormonal contraceptives. Obstet. Gynecol. 2011, 117, 363-371. [CrossRef]

43. American College of Obstetricians and Gynecologists. Committee opinion no. 539: Adolescents and long-acting reversible contraception: Implants and intrauterine devices. Obstet. Gynecol. 2012, 120, 983-988. [CrossRef] [PubMed]

44. Dickerson, L.M.; Diaz, V.A.; Jordon, J.; Davis, E.; Chirina, S.; Goddard, J.A.; Carr, K.B.; Carek, P.J. Satisfaction, early removal, and side effects associated with long-acting reversible contraception. Fam. Med. 2013, 45, 701-707. [PubMed]

45. Peterson, H.B.; Cates, W. Evidence-based medicine in action: The United States Selected Practice Recommendations for Contraceptive Use. Contraception 2013, 87, 509-510. [CrossRef] [PubMed] 
46. Battaglia, C.; Battaglia, B.; Casadio, P.; Rizzo, R.; Artini, P.G. Metformin metabolic and vascular effects in normal weight hyperinsulinemic polycystic ovary syndrome patients treated with contraceptive vaginal ring. A pilot study. Gynecol. Endocrinol. 2020, 36, 1062-1069. [CrossRef]

47. Morotti, E.; Casadio, P.; Guasina, F.; Battaglia, B.; Mattioli, M.; Battaglia, C. Weight gain, body image and sexual function in young patients treated with contraceptive vaginal ring. A prospective pilot study. Gynecol. Endocrinol. 2017, 33, 660-664. [CrossRef]

48. Battaglia, C.; Morotti, E.; Persico, N.; Battaglia, B.; Busacchi, P.; Casadio, P.; Paradisi, R.; Venturoli, S. Clitoral vascularization and sexual behavior in young patients treated with drospirenone-ethinyl estradiol or contraceptive vaginal ring: A prospective, randomized, pilot study. J. Sex. Med. 2014, 11, 471-480. [CrossRef]

49. Amico, J.R.; Bennett, A.H.; Karasz, A.; Gold, M. Taking the provider "out of the loop:" patients' and physicians' perspectives about IUD self-removal. Contraception 2018. [CrossRef]

50. Godfrey, E.M.; West, I.I.; Holmes, J.; Keppel, G.A.; Baldwin, L.M. Use of an electronic health record data sharing system for identifying current contraceptive use within the WWAMI region Practice and Research Network. Contraception 2018, 98, 476-481. [CrossRef] 